\title{
Nutrition, Nitrogen Requirements, Exercise and Chemotherapy-Induced Toxicity in Cancer Patients. A puzzle of Contrasting Truths?
}

\author{
Vincenzo Flati ${ }^{\mathrm{a}}$, Giovanni Corsetti ${ }^{\mathrm{b}}$, Evasio Pasini $^{\mathrm{c}}$, Anna Rufo $^{\mathrm{a}}$, Claudia Romano ${ }^{\mathrm{b}}$ and \\ Francesco Saverio Dioguardi ${ }^{\mathrm{d} *}$
}

\begin{abstract}
${ }^{a}$ Department of Biotechnological and Applied Clinical Sciences, University of L'Aquila, L'Aquila, Italy; ${ }^{b}$ Human Anatomy \& Physiopathology Unit, Department of Clinical \& Experimental Sciences, University of Brescia, Brescia, Italy; ${ }^{c}$ Fondazione Salvatore Maugeri, IRCCS, Cardiology Rehabilitative Division, Medical Centre of Lumezzane, Brescia, Italy; 'Dipartimento di Scienze Cliniche e di Comunità, Università degli Studi di Milano, Milano, Italy
\end{abstract}

Abstract: Amino acids can modulate cell metabolism and control cell fate by regulating cell survival and cell death. The molecular mechanisms involved are mediated by the mTOR complexes mTORC1 and mTORC2 activity. These complexes are finely regulated and the continuous advancement of the knowledge on their composition and function is revealing that their balance may represent the condition that determines the cell fate. This is important for normal healthy cells but it is becoming clear, and it is even more important, that the balance of the mTORCs activity may also condition the cell fate of cancer cells. Here, we discuss the evidences supporting the amino acids supplementation as a cancer fighting weapon and a possible strategy to counteract the myocyte toxicity associated with chemotherapy, possibly by tipping the balance of mTORCs activity.

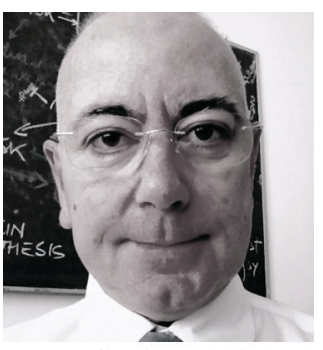

F.S. Dioguardi

Keywords: Amino acids, cancer, chemotherapy, heart doxorubicin, mTOR, nutrition, exercise.

\section{INTRODUCTION}

We know that malnutrition correlates with poor quality of life, increased mortality and morbidity and chemotherapy-induced toxicity in cancer patients $[1,2]$. Conversely, recent studies have shown that calorie restriction counteracts the development of cancer in experimental models [3] and similar positive results have been obtained by introducing specific nutrient supplements and physical exercise [4]. Evidences concerning nutrition and altered protein/ nitrogen metabolism in cancer have been described since the 50's [5-7] generating the important concept that "the host-tumor relationship is the key to the cancer problem" [8]. This would suggest a possible link between nutritional habits and cancer development $[9,10]$. Hence, the main question regarding the hostcancer relationship can be asked: "nutrients feed best cancer or noncancer tissues ?" [11].

\subsection{Muscle and Visceral Proteins as a Protein/Nitrogen} Reservoir, which Regulates Global Body Metabolism

Until only a few years ago, the muscle was considered a tissue which was solely responsible for body movements, but understanding the metabolic role of muscle in the body has now increased considerably. There is much evidence that the muscle is an organ also fundamental to maintain protein and glucose metabolism. Indeed, the muscle is the most important reservoir of nitrogen as each amino acid contains at least one amino group (NH2). Nitrogen is also necessary for pyrimidine and purine synthesis which build up nucleic acids and energetic molecules such as ATP. Furthermore, nitrogen derived from amino acids is essential for producing Nitric Oxide (NO), which is an important regulatory molecule for blood circulation, neuro transmission [12] and macrophage cytotoxic activity against microbes and tumor cells. NO also acts on the muscle, by modulating its structure and

*Address correspondence to this author at the Dipartimento di Scienze Cliniche e di Comunità, Università degli Studi di Milano, via San Barnaba 8, 20122 Milano, Italy; Tel: ++39-02-58318096;

E-mail: fsdioguardi@gmail.com function and by stimulating mitochondria biogenesis [13]. The importance of the muscle in maintaining global metabolism has been confirmed by the fact that many catabolic/anabolic hormone receptors are located in this tissue. In addition, the muscle is metabolically linked with the liver, kidney, fat tissue and lungs to produce metabolic intermediaries fundamental for whole body functions.

Cancer patients with muscular wasting, sarcopenia and cachexia have an altered balance of circulating anabolic (i.e., insulin, insulinlike growth factors, growth hormones and others) and catabolic molecules (i.e., TNF-alpha, cortisol, catecholamines, glucagons and cytokines such as interleukins and others) that alter the ratio between anabolism and catabolism. This altered ratio might be indicated as the "Cancer-related hypercatabolic syndrome, C-RHS" that is characterized by significant changes in both the muscular and global visceral protein metabolism $[14,15]$. Interestingly, the continuous turnover of proteins is a process at the root of cell life in healthy individuals. For instance, in healthy humans, about 250$350 \mathrm{~g}$ of protein are degraded in the muscles every day. Some of the amino acids (AAs) produced are reused by the cells for new protein synthesis or to produce energy-rich intermediates for oxidation via the Krebs cycle and the respiratory chain, but a large quantity of AAs are released into the blood to maintain the blood pool of AAs. The balance between muscle protein synthesis and breakdown determines the overall cell protein/nitrogen content and metabolism. The increase of catabolic hormones and/or molecules and the reduction of anabolic hormones, in the C-RHS, causes muscular proteolysis and AAs release that have various metabolic consequences, including insulin resistance, reduced cytoplasmic and mitochondrial protein synthesis as well as impaired cell function and energy metabolism. The impairment of protein muscle and global metabolism in cancer patients has recently been demonstrated. Cancer patients have massive muscle proteolysis with consequent AA release which causes lean mass muscle loss. Indeed, the fundamental role of muscle in whole-body protein metabolism has recently been pointed out by Wolfe who wrote that "it is imperative the maintenance of muscle mass, strength and metabolic function by specific strategy such as physical activity and 
diet" [16]. Regarding visceral proteins, we have known since the seminal studies of Babson and Winnick [17] that tumors preferentially use macromolecules, to free amino acids. Albumin is the preferred cell source of amino acids as it is the most abundant protein in the circulating plasma accounting for about $50-70 \%$ of human plasma protein reserve. Pinocytosis has been identified as the main process used by neoplastic cells to match their nitrogen needs. Modulation of the pinosome-lysosome pathway activity is a homeostatic mechanism sensitive to the availability of extracellular free amino acids, whose role has been found in normal cells, but whose potential has not yet been explored in cancer-bearing states. Tumor mass has an extremely elevated filtration pressure, several times higher than that of kidney mesangial cells, and as a result amino acids will pass through the mass at an extremely high speed. This would explain why circulating protein metabolism may be particularly affected in cancer patients, as tumor cells can nourish themselves primarily by pinocytosis of more slowly filtered protein macromolecules, which are degraded by lysosomal cathepsin B. In normal cells this process is inversely proportional to the availability of free amino acids in the plasma. Under these conditions, the liver increases consumption of circulating amino acids in an attempt to maintain the plasma concentration of albumin constant, with the consequence that this "vicious circle" wastes either energy or essential amino acids $[18,19]$. Nevertheless, we have to consider that neoplastic cells consume high amounts of proteins, particularly in function of the size of the tumor. For instance, a tumor of $8.8 \%$ of body weight has a daily nitrogen balance equivalent to $150 \%$ of the daily retention obtained from the diet [20]. Cancer treatment with nutritional support is not yet well established as a clinical practice and dedicated guidelines are not yet available. However, malnutrition treatment, including nutritional supplementation and physical exercise, should be started as early as possible in cancer patients. Several studies indicate that selected nutrients, such as amino acids, are not simply a caloric supply, but may interfere with different mechanisms implicated in the pathogenesis of cachexia. In fact, oral ingestion of essential amino acids elicits important physiological responses and favorable changes in the balance between anabolic and catabolic hormones. It has been shown that this balance is significantly modified by both acute or chronic ingestion of amino acids [21, 22]. Moreover, there is growing evidence that amino acids influence gene transcription and translation, so, by directly modulating the effects of hormones and energy availability, the amino acids can potentially control protein wasting and cachexia [23].

AAs in the diet are absorbed after protein digestion by pancreatic enzymes. However, the pancreas uses large amounts of AAs and energy to produce digestive enzymes [15]. In cancer patients, the efficiency of the pancreas and mesenteric circulation may be progressively reduced. These conditions can lead to impaired AA digestion and absorption and consequently, to reduced AA content in the plasma that may be insufficient to maintain protein synthesis and energy needs [15]. Therefore, increased protein- intake with meals does not necessarily increase muscle and visceral protein synthesis. On the contrary, individual AAs provided through nutritional supplements do not need to be digested. They are rapidly absorbed and are therefore immediately available in the bloodstream and transported into cells [15]. In addition, we know that specific AAs have multiple metabolic roles that go beyond their simple role as building blocks for protein synthesis. Essential amino acid (EAAs) stimulate protein synthesis in both the young and elderly with or without diseases [24]. It has been recently demonstrated that specific mixtures of individual AAs, including essential ones, calculated according to defined stoichiometric ratios between amino acids and nitrogen content, are also capable of: 1) meeting energy needs, 2) maintaining protein syntheses and/or 3) stimulating mitochondrial biogenesis [25, 26]. These results may be due to the fact that certain AAs can control protein synthesis in myocytes. They do this by activating AMPactivated protein kinase (AMPK) and the mammalian target of rapamycin, mTOR. This activity is anabolic and counteracts the catabolic stimulation of hormones, cytokines and specific molecules produced by neoplastic cells [27]. An increasing number of studies on the positive metabolic role of amino acids in cancer have been published [28]. The practical clinical consequence of these observations is that calorie and nitrogen needs should be calculated separately, as indicated out by Layman, rather than just calculating nitrogen needs as a percentage of calories provided by the diet [29].

Furthermore it is important to note that physical activity improves muscle mass and strength and can be recommended in sarcopenic and cachectic patients, together with other therapeutic strategies. In particular, aerobic exercise increases both mitochondrial activity and number, while resistance exercise improves musclemass and strength by increasing proteins synthesis and fiber size and by stimulating the mTOR pathway [30].

Thus, nutritional supplementation and physical activity could be synergic strategies to improve the protein/nitrogen ratio in cancer patients to both maintain body metabolism and to counteract chemotherapy induced toxicity in muscles.

\subsection{Amino Acids Supplementation as a Cancer Fighting Weapon}

Researchers have identified in mammalian target of rapamycin (mTOR) the main intracellular mediator of cancer development induced by nutrition [31]. mTOR is not only activated by nitrogen substrates, provided by digestion of macronutrients, but also by various stimuli, such as growth factors and energy stress. For these reasons, mTOR is at the center of a complex network that controls protein synthesis, cell differentiation, growth and proliferation [3133]. However, other evidence suggest that mTOR may also play a positive role in cancer patients. It has been demonstrated that physical exercise stimulates the mTOR pathway and this is correlated with the prevention of certain type of cancers [34-36]. mTOR can also increase tolerability of chemotherapy and can protect against autophagy (frequently associate with cancer resistance to therapy) and improve prognosis [37-39]. It is interesting that, it has been recently proposed that physical exercise and nutrients, such as amino acids, maintain protein synthesis and anabolism because they activate different pathways upstream of mTOR [30]. Indeed, specific amino acid mixtures activate the mTOR kinase cascade that ultimately results in phosphorylation of the ribosomeassociated S6 kinase. Activation of the S6 kinase permits a high level of translation of mRNA species that encode ribosomal proteins, activating both amino acids cell entry and protein synthesis [30]. In addition, physical exercise acts by avoiding protein disarrangement. The balance between synthesis and catabolism of proteins (mainly muscular but also visceral) is relevant in maintaining global bodymetabolism and integrity as well as the contractile function of myocytes. This can avoid malnutrition and sarcopenia [40], which are common negative features of cancer that influence and worsen chemotherapy side-effects [41-43]. Furthermore, the maintenance of muscle-cell integrity is extremely important in cancer, since many patients do not receive adequate chemotherapy due to myocyte toxicity. Chemotherapy-induced cardiotoxicity that has been reported since the beginning of the use of chemotherapy is one example of this [44].

The apparent discrepancies between the pro-cancer and anticancer action of mTOR is probably due to the fact that it functions through multi-protein complexes. mTOR manages many different messages by entering into two different multi-subunit complexes; mTORC1, localized on the outer membrane of lysosomes and mTORC2, whose function requires to be associated with ribosomes. The recent knowledge that mTORCs may act either synergistically, 
independently or also antagonistically, according to the prevalence of signaling pathways is another interesting development.

The complexity of TORCs regulation seen from those findings, may explain the problems encountered in using rapamycin or rapalogues in fighting cancer $[45,46]$.

More in detail, mTOR is a highly conserved serine-threonine kinase that belongs to the PIKK (phosphoinositide 3-kinase related protein kinase) super-family, which includes several large-sized kinase proteins involved in nutrient sensing and DNA repair [4749]. mTOR functions as the catalytic subunit of two distinct protein kinase complexes, designated as mTORC1 (mTOR complex 1) and mTORC2 (mTOR complex 2). Both mTORC1 and mTORC2 complexes comprehend common subunits, including the mTOR catalytic subunit and mLST8 (mammalian lethal with sec-13 protein 8 , also known as G $\beta \mathrm{L}$ ), whereas other elements distinguish them. In particular, mTORC1 contains Raptor (regulator-associated protein of mammalian target of rapamycin) [50] and PRAS40 [5153], whereas mTORC2 contains Rictor (rapamycin insensitive companion of mTOR), Protor ( 1 or 2 and acts as a Rictor-binding protein) [54] and mSin 1 (mammalian stress activated map kinaseinteracting protein 1, also called MAPKAP1) [55-57]. Both complexes are negatively regulated by Deptor. On the other hand mTORC1 and mTORC2 negatively regulate Deptor expression for their activity modulation [58, 59]. Nevertheless, most of the literature so far published has concentrated on mTORC1 and for this reason it is the best characterized. mTOR is activated by different stimuli, such as nutrients, growth factors, energy and stress signals, exercise and as a result mTORC1 mediates these effects on growth and proliferation. The amount and quality of nutrients trigger either energy-consuming anabolic pathways under nutrient sufficiency, or alternatively energy-producing catabolic pathways under stress conditions or starvation. mTORC1 is in general, activated under nutrient-rich conditions and its function is blocked under nutrient-limiting conditions, and carefully integrates these signals to control many fundamental processes involved in cellular metabolism and growth by phosphorylating and therefore activating p70S6 kinase. This, in turn, phosphorylates ribosomal S6 protein, leading to increased protein synthesis. The activated mTORC1 also mediates the phosphorylation of eIF4E-binding protein 1 (4E-BP1) and promotes the formation of the active protein synthesis initiation complex [60]. In addition, glucose availability and the fluctuation of energy is sensed by the AMP-activated protein kinase (AMPK), which works coordinately with mTORC1 by shifting the cells to catabolic metabolism [61].

As we have already mentioned, nutrients are crucial signals in regulating $\mathrm{mTORC} 1$ and in particular, amino acids (AAs) are essential for mTORC1 activation. In fact, growth factors and other stimuli cannot efficiently activate mTOR when AAs are limited $[62,63]$. The specific AAs that are required and how they trigger their signals to mTOR are at present under study, nevertheless it is widely accepted that the essential AA leucine is crucial for mTOR signaling [64] and that glutamine is required for extracellular leucine to start the signal [65]. However, it is not yet well understood in which cell compartment the amino acids should be located or how they are sensed. One possibility is that AAs accumulate inside the lysosomal lumen (i.e. as the result of protein degradation) and here are sensed by a large multisubunit vacuolar $\mathrm{H}+$-adenosine triphosphate ATPase (v-ATPase). This macromolecular system, consisting of V1 and V0 domains, is essential in maintaining the low pH necessary for the lysosome to work properly and appears to have a role downstream of intracellular amino acids in the initiation or propagation of the amino acid-induced signal to mTORC1. In particular, it has been shown that V0 and V1 subunits, in presence of AAs, are associated with Rag GTPase and Ragulator complex, leading to mTORC1 activation [66]. Rag proteins are members of the Ras family of GTPases and exist in four variants (RagA-D). A Rag dimer, consisting of an $\mathrm{A} / \mathrm{B}$ subunit bound to a $\mathrm{C} / \mathrm{D}$ subunit, binds mTORC1 in the presence of AAs in the lysosome [67]. In particular, AAs promote Rag activation, where Rag A/B is loaded with GTP and Rag C/D is loaded with GDP, thus causing the recruitment of mTORC1 to the lysosomal membrane through the Ragulator complex [68]. The Ragulator complex is a scaffolding protein consisting of five subunits, namely p18, p14, MP1, C7orf59 and HBXIP. Considering that a key event in the amino aciddependent activation of mTORC1 is the conversion of Rag A/B from a GDP- to a GTP-bound state, the discovery that Ragulator has a guanine nucleotide exchange factor (GEF) activity towards Rag A/B, could be a crucial step [69] towards fully understanding this complex mechanism. After recruiting at the lysosome, mTORC1 requires another small GTPase called Rheb [70,71] for its activation. Rheb is modulated by the tuberous sclerosis complex (TSC1/2), which basically works as a GTPase activating protein. Because the TSC complex is normally deactivated by the PI3K pathway in presence of growth factors, also through AKT-mediated phosphorylation, the full activation of mTORC1 can only be achieved in the presence of both amino acids and growth factors $[72,73]$. Exactly how AAs modulate mTORC1 is now the subject of extensive debate and study. There have been many publications identifying new factors which are potentially involved in this pathway and there are reviews that summarize these findings very clearly $[74,75]$. Although the hypothesis of mTORC1 activation at the lysosomal membrane is currently the most experimentally accredited, a very recent in vitro study demonstrates that the activity of mTORC1 in Rag-depleted cells is maintained outside the lysosomes if the cells are cultured in a complete medium [76]. The same authors found that leucine starvation did not alter the punctate localization of mTORC1 at the lysosomes, unlike starvation for all AAs. However, as yet said, leucine appears to be essential to activate mTORC1, independently of its localization.

It is therefore clear that regulation of mTORCs by AAs is a topic which is continuously developing and the common element of all these studies appears to be the stimulating effect of AAs on mTORC1. Consistent with the critical role of mTOR in regulating cell growth and metabolism, its pathway is frequently activated in human cancers $[77,78]$. As a result, nutrients and in particular AAs could play a crucial role in regulating both physiological and pathological conditions.

The question we need to ask ourselves, is: do AAs always activate only mTORC1, leading to stimulation of cell growth and proliferation through anabolism, regardless of their type or molar ratio? Some and quite recent studies, we shall look at, have shown that the regulation of mTOR function is much more complex and articulated than previously thought.

Oral supplementation with BCAAs (branched chain AAs, i.e. leucine, isoleucine and valine), is epidemiologically associated with a lower incidence of hepatocellular carcinoma in cirrhotic patients [79]. Other interesting studies in vitro, conducted mainly on cells of hepatic origin, tried to provide a mechanism of such action of BCAAs. In particular, media containing BCAAs and with an appropriate Fischer's ratio (that is the molar ratio of BCAAs leucine, valine, isoleucine to aromatic AAs phenylalanine, tyrosine), seem to possess specific activity on hepatoma cell lines, inducing premature senescence of cells at risk of neoplastic transformation. In particular the $\mathrm{p} 21 \mathrm{CIP} 1 / \mathrm{WAF} 1$ protein level is strongly upregulated by DNA damage induced by chemotherapeutic drugs only in the presence of BCAAs, while increased $\mathrm{p} 21$ protein is suppressed by rapamycin. These results would indicate that BCAAs positively modulate premature senescence of cells at risk of neoplastic transformation by upregulating $\mathrm{p} 21$ through the mTORC1 pathway. As a result chemotherapeutic drugs treatment combined with 
BCAAs enhances the execution of premature senescence in cells at risk of neoplastic transformation and decreases the incidence of hepatocellular carcinoma [80].

In another study, BCAAs directly prevent insulin-induced cell proliferation of hepatoma cell lines by suppressing the insulin signaling pathway. This effect is attributed to an enhanced apoptosis by antagonizing the anti-apoptotic function of insulin and the molecular mechanisms of how BCAA suppresses insulin/PI3K/ Akt pathway is dependent on both mTORC1 and mTORC2 activities. In particular BCAAs function as suppressors of the PI3K/Akt pathway by both inducing a negative feedback loop through mTORC1/S6K1 activation and by suppressing mTORC2 kinase activity towards Akt, although the mechanisms involved with mTORC2 suppression by BCAA are only conceivable [81].

Nishitani and co-workers looked at hepatocellular carcinoma cells expressing the EpCAM marker of cancer stem-cells. In the presence of BCAAs with a high Fischer's ratio, the percentage of EpCAM-positive cells was significantly reduced and this effect was mimicked by prolonged treatment with rapamycin. Further experiments on Raptor and Rictor knockdown cells seem to show a prominent role of $\mathrm{mTORC} 2$ in reducing tumorigenesis, possibly hampered by the activation of mTORC 1 and, consequently, of p70S6 kinase, through inactivation of Rictor [82]. It has also been reported that activation of p70S6 kinase feedback loop inhibits Rictor phosphorylation, resulting in the suppression of Rictor function [83]. As a result, impaired mTORC2 causes a reduction in the phosphorylation of Akt at serine 473, whose phosphorylation is significantly correlated with cancer stemness [84, 85]. These studies underline the increased interest in mTORC2 for its implications in tumorigenesis, however [86], they have also stimulated new ideas on the role played by the amino acids, or some of them in particular, on the pathological mechanisms that lead to cancer or to its prevention.

On the other hand, mTORC2 senses extra-cellular growth factor stimulation through molecular mechanisms that are still largely unclear. It is known that, once activated, it phosphorylates several major downstream target proteins including AGC family of kinases, such as Akt (also known as Protein Kinase B, PKB), SGK (Serum and Glucocortioid induced Kinases) and PKC (protein kinase $\mathrm{C}$ ) [87-89]. Furthermore, in a recent paper, mTORC2 was shown to respond to amino acids through the PI3K/AKT pathway [90]. The authors found that by using different starvation conditions, amino acids can selectively activate mTORC1 or mTORC2.

It is becoming increasingly clear that the mTORC complexes 1 and 2 work in a very coordinated and tightly controlled way to regulate cell metabolism, growth and ultimately cell fate (survival or death). Among the effects mediated by mTORC1, it is now well established that, via mTORC1, mTOR negatively regulates autophagy in presence of nutrients. Nevertheless, very recently, it has been reported that $\mathrm{mTOR}$ can also operate independently through the mTORC2 complex to promote autophagy [91] when amino acids availability is limited. It has also been shown that mTOR activity is inhibited at the beginning of the autophagy process but when starvation is prolonged mTOR is reactivated despite ongoing starvation. Under these conditions the role of mTORC1 shifts from repressor to become activator of autophagy [92] and the reactivation of mTOR is dependent on amino acids as the end products of autolysosomal degradation.

Under experimental conditions, fasting for 72 hours decreases mTORC1 signaling and this is followed by increased protein breakdown and a trend towards reduced protein synthesis. However, the observed effects on autophagy were contradictory: LC3B-I conversion to LCB3B-II was significantly increased, although the expected p62 decrease, indicating increased flux towards autophagy, was not recorded as there was a slight but constant increase. As a result, the conclusions about short term fasting and autophagy control [93] remain elusive.

In response to growth factor stimulation, mTORC2 has been found to phosphorylate Akt on S473, and the protein Rictor (a specific component of mTORC2 and not of mTORC1) has been demonstrated to be required for this activity [94]. Although this establishes a direct link between mTOR and Akt activity, it also shows that the mTOR pathway regulation is more entangled than previously thought. The interplay between different degrees of the mTORC1 /mTORC2 complexes activation could shift a cell's fate from survival to death and vice-versa. The activation of the mTORC1 complex could antagonize activity of mTORC2 complex thereby reducing Akt phosphorylation on S473 and its signaling. Furthermore, the mTORC1 can negatively regulate mTORC2 through indirect mechanisms involving a negative feedback loop directed to phosphorylation of insulin receptor substrate 1 (IRS1) [95] as well as through the phosphorylation of the growth factor receptor-bound protein 10 (Grb10), which blocks the PI3K pathway $[96,97]$. Yu and his co-workers suggest that Grb10 might be a tumor suppressor regulated by mTORC1. We can deduce that mTORC1 can exert tumor suppressor activities through the modulation of intermediate activity. It has also been reported that mTORC1 can negatively regulate mTORC2 through direct mechanisms mediated by phosphorylation of SIN1 (another specific component of mTORC2 and not of mTORC1) [98]. Thus the resulting Akt suppression leads both to increased levels of cleaved caspase 3 and to apoptotic cell death. This in turn increases sensitivity to chemotherapy agents such as etoposide and cisplatin.

In our laboratory we have obtained preliminary data indicating that specific AAs mixtures can induce colon carcinoma HCT116 cell death. Indeed in these cells an increased amount of cleaved caspase 3, after treatment with AAs, was detected. In our experimental setup, the amino acids (for the detailed mixture composition see ref [99]) are provided exogenously in elevated quantities. Under these conditions the mTORC 1 is activated as previously observed [100, 101]. We hypothesize that as a result of the imbalance between Essential AA (EAA) and NonEAA provided to cells by our protocol, the $\mathrm{mTORC} 1 / 2$ ratio is altered thus triggering the increased cleavage of caspase 3 . In the same cell line we also observed a large increase of the Bax/Bcl2 ratio after AAs treatment (Fig. 1). This further supports the idea that AAs, rather than acting by activating protein synthesis, can promote apoptosis of cancer cells, at least in vitro, through mechanisms that need to be further clarified.

Although mTORC1 is the acquired sensor activated by amino acids [102], a recent work reports that TORC2 can also be activated by amino acids [90]. In light of the complex machinery illustrated in the Fig. 2, we believe that amino acids induce and maintain the negative loops upstream of mTORC1 and TORC2 so that their function is strictly regulated. A further mechanism of mTORCs activity control involves the protein Deptor. This is an endogenous inhibitor of mTORC1 and mTORC2 but when it is expressed at high levels the activity on mTORC2 flips from inhibitor to activator possibly by reactivating the PI3K/mTORC2/Akt signaling [58,59]. The preferential inhibitory activity of Deptor versus mTORC1 could represent a valuable tool to be leveraged in order to achieve cancer cell growth inhibition and possibly cancer cell death and, at the same time, leaving the healthy cells undamaged. We hypothesize that the amino acids could also act on this mechanism of mTORCs regulation in order to maintain homeostasis of healthy cells and to promote cancer cell death. However, the main question remains whether amino acids per se, or unbalancing the ratio of certain types of amino acids over others, are relevant in promoting any advantages or disadvantages in the epigenetic regulation of cell health. Current study in our laboratory hopes to answer this important question. 

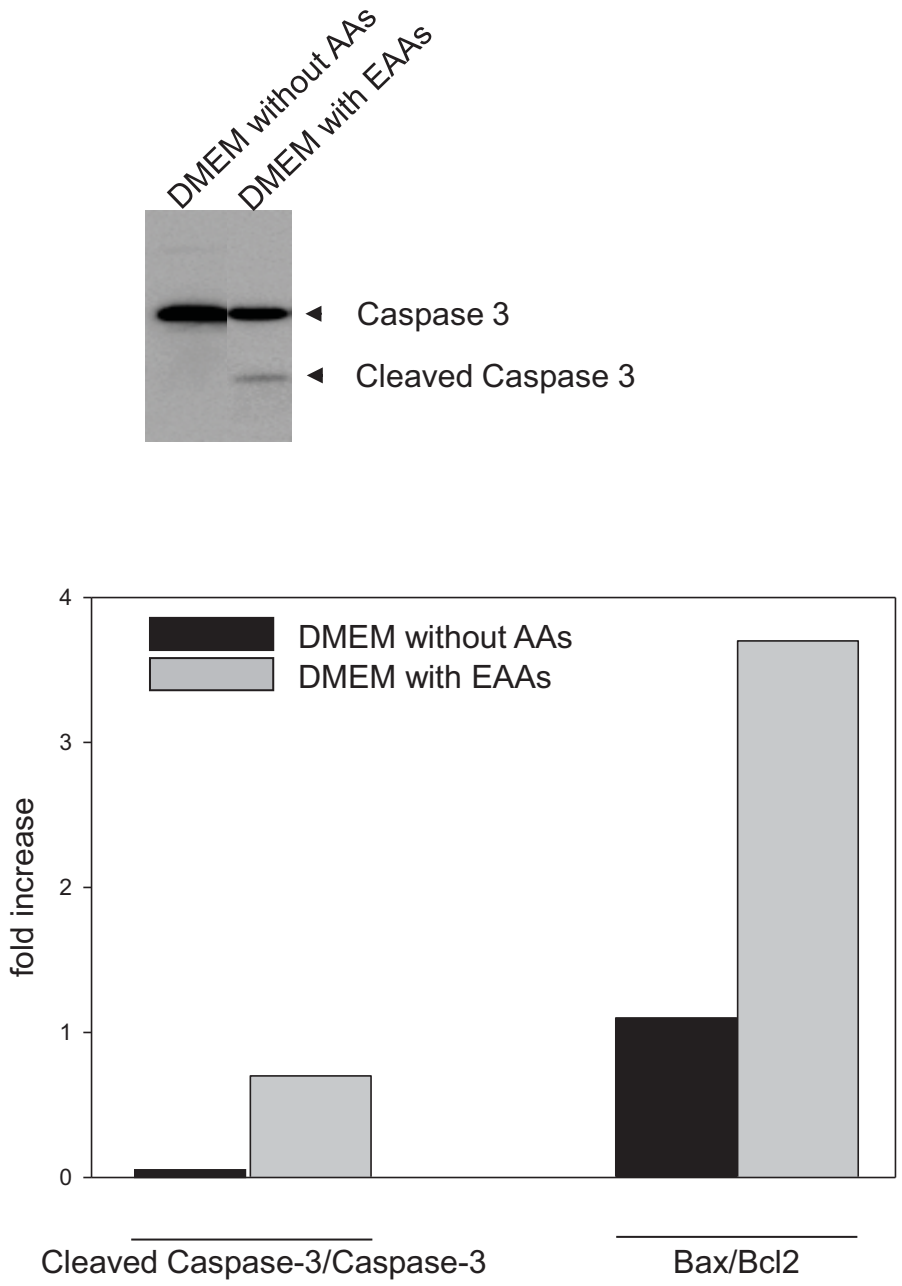

Fig. (1). Preliminary data indicating that specific amino acid mixtures can induce colon carcinoma HCT116 cell death. It is evidenced as an increased amount of cleaved caspase 3 and a large increase of the Bax/Bcl2 ratio.

\subsection{Chemotherapy Induced Toxicity: Doxorubicin effects and Prevention of Myocyte Toxicity by Essential Amino Acids}

Anthracyclines are a class of widely used and effective anticancer drugs [103] essential for the treatment of acute leukemia, Hodgkin's and non-Hodgkin's lymphoma and breast cancer. Among these anthracyclines, Doxorubicin (Doxo) is the most widely prescribed and effective cytotoxic drug presently used in oncology. Unfortunately, the clinical utility of conventional anthracyclines is limited by their high toxicity and in particular by a dose and time dependent progressive induction of congestive heart failure (CHF) [104, 105]. An example, is a study of a cohort of 607 children treated with anthracyclines, showing that patients treated with a cumulative dose of anthracyclines higher than $300 \mathrm{mg} / \mathrm{m}(2)$ were at high risk of CHF and 15 years after treatment, up to $5 \%$ of the patients develop anthracycline-induced CHF. The estimated risk of CHF increased with time after the beginning of anthracycline chemotherapy [106, 107]. This evidence reinforces the need for strategies for early detection of chemotherapy-induced CHF and to evaluate other chemotherapeutic strategies or cardio-protective agents in order to achieve better survival rates.

\subsection{Mechanisms of Anthracyclines/Doxo Toxicity}

\section{a) Toxicity in Cancer Cells}

The mechanisms of action of anthracyclines in tumor cells remain vague. However several mechanisms have been proposed including: generation of free radical and reactive oxygen species
(ROS), leading to DNA damage or lipid peroxidation; DNA intercalation, leading to inhibition of macromolecules synthesis; DNA binding and alkylation; DNA cross-linking and interference with its replication. The hypothesis that ROS may be mediators of tumor cell death induced by anthracyclines has been questioned by studies in which treatment with ROS scavenger failed to reduce Doxo toxicity in tumor cells [reviewed in 108]. As a result, ROS production does not seem to be the major cause of tumor cell death induced by anthracyclines.

The Doxo's main cellular target is the topoisomerase-II (Top2) [109]. Doxo binds both DNA and Top2 to form the ternary Top2Doxo-DNA cleavage complex, which triggers cell death. There are two Top 2 enzymes: Top $2 \alpha$ and Top $2 \beta$. Top $2 \alpha$, is a known marker of cell proliferation, being overexpressed in tumors and being not detectable in quiescent tissues. Therefore, Top $2 \alpha$ is thought to be the molecular target of Doxo's anticancer activity $[110,111]$. Adult mammalian cardiomyocytes express Top $2 \beta$ but no detectable Top $2 \alpha$. Top $2 \beta$ is also a target for doxorubicin, and the Top $2 \beta$ doxorubicin-DNA ternary cleavage complex can induce DNA double-strand breaks leading to cell death. Cardiomyocyte-specific deletion of Top $2 \beta$ protects mice from the development of Doxoinduced progressive heart failure, suggesting that Doxo-induced cardiotoxicity is mediated by Top $2 \beta$ in cardiomyocytes [110].

\section{b) Toxicity in Healthy Muscle/Heart Cells}

Although it is still not yet fully clear, the mechanism responsible for Doxo-induced muscle and cardio-toxicity seems to 


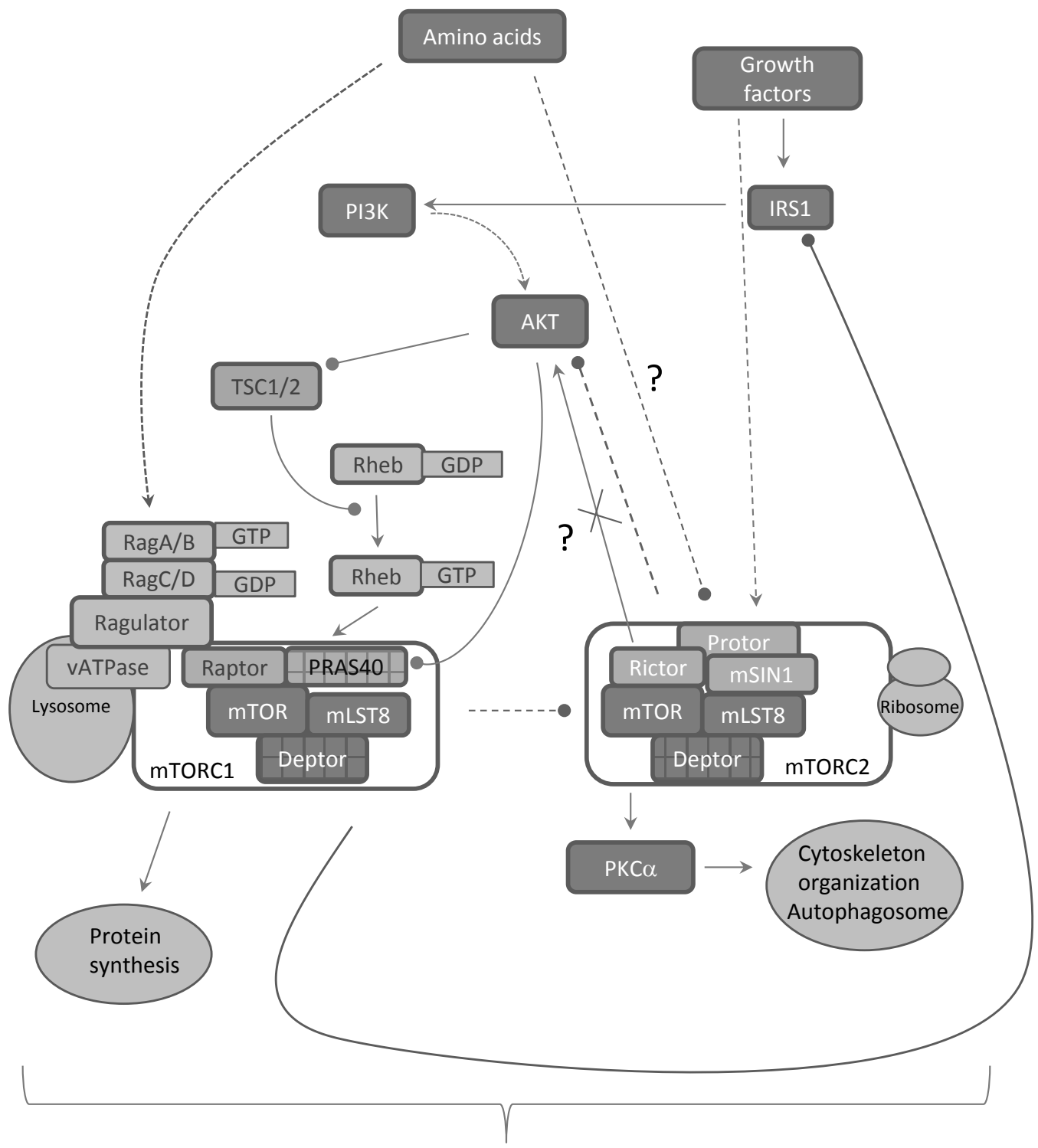

Caspase 3

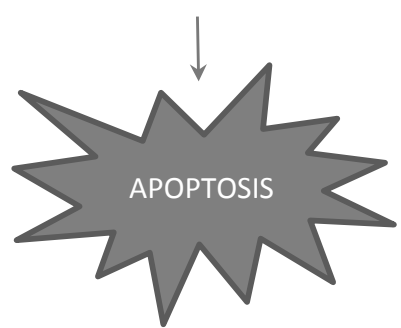

Fig. (2). Interplay between mTORC1 and mTORC2 in mediating the molecular effects of amino acids (please refer to the text for explanation).

be very different from that involved in antitumor activity. Doxo reduces the expression of a variety of muscle-specific proteins, including contractile proteins, sarcoplasmic reticulum proteins and mitochondrial proteins. Loss in muscle myofibrillar proteins is associated with reduced contractility and may explain the pathologic features of Doxo-induced cardiomyopathy. The damaging effects of Doxo change the morphology of the cardiomyocytes that manifest themselves as dilation of heart chambers, fibrosis, vacuolization, reduced myofibrils, mitochondrial disruption and chromatin disorganization [108]. The main cardiomyocyte organelles damaged by Doxo are the mitochondria, where the drug accumulates [112, 113]. Many mechanisms for Doxo-induced cell injury have been proposed $[110,114,115]$. One major hypothesis is that oxidative stress is generated through interaction with iron and oxygen. Administering Doxo to laboratory animals [116-118] and humans [119-122] increased plasma and tissue ROS and lipid peroxidation 
products but decreased plasma and tissue anti-oxidant levels. Most studies support the view that Anthracyclines/Doxo increase ROS and lipids peroxidation by interacting with mitochondrial enzymes, therefore inhibiting nucleic acid, protein synthesis and mitochondrial function $[108,123,124]$. It seems that ROS also play a key role in the pathogenesis of Doxo induced cardiomyopathy. The heart is particularly susceptible to Doxo-induced oxidative damage because of the large density/volume of mitochondria. These are both important sources and targets of ROS, given their high rate of oxygen consumption and lower antioxidant defenses in the heart compared with other organs, such as the liver $[125,126]$. Many intracellular enzymes can mediate Doxo effects. These include, the microsomal nicotinamide adenine dinucleotide phosphate (NADPH)cytochrome $\mathrm{P} 450$ reductase, which is a primary site for ROS generation from a chemically diverse group of compounds including many anti-neoplastic agents. NADPH-dependent microsomal enzymes are present in all tissues. In cardiac cells, however, due to a mitochondrial nicotinamide adenine dinucleotide (NADH) dehydrogenase that is not present in other types of cells, this enzyme generates very high levels of free radicals in the presence of doxorubicin. This may explain the high degree of oxidative stress that the drug causes in cardiac mitochondria. Therefore, the specific structure of the electron transport system of cardiac mitochondria is responsible for the high level of oxidative stress generated by Doxo and for the development of cardiomyopathy [127].

\subsection{Prevention of Anthracycline/Doxo-induced Toxicity}

At present, there is no specific treatment for Anthracyclines/ Doxo induced cardiomyopathy. Doxo-induced cardiomyopathy is refractory to conventional therapy [128], although $\beta$-blockers and angiotensin-converting enzyme (ACE) inhibitors may be useful in patients with congestive heart failure [129, 130]. Cardiac transplantation remains the last option for patients with end-stage heart failure due to Doxo cardiomyopathy [130, 131-133].

The first line of defense against cardiotoxicity remains, whenever possible, the containment of the cumulative dose below $450 \mathrm{mg} / \mathrm{m} 2$. For this purpose, numerous therapeutic strategies have been proposed (using Doxo analogues, antioxidants, iron chelators, etc.) [108] but none has been particularly successful. However, the administration of antioxidants has proved to be effective to prevent damage in acute Doxo intoxication. Recent evidence has shown that carotenoids (50 and $100 \mu \mathrm{g} / \mathrm{kg}$ ) could prevent the acute cardiotoxicity and hepatotoxicity induced by Doxo ( $25 \mathrm{mg} / \mathrm{kg}$ i.p.) in tumor bearing mice [134]. Presently, dexrazoxane is the sole clinically approved cardioprotective agent against anthracycline-induced cardiotoxicity. Its activity has been attributed to the iron-chelating effects of its metabolite which protect against oxidative stress. However, dexrazoxane is also a catalytic inhibitor of Top2 and recent findings show that dexrazoxane may protect cardiomyocytes via its catalytic Top2 inhibitory activity rather than iron-chelation activity [111].

Recently, researchers have focused on the development of liposomal anthracyclines to mitigate the life threatening effects of conventional anthracyclines. In particular, pegylated liposomal Doxo (PLD), has proven to be an effective anti-tumor drug for metastatic breast and ovarian cancer, with less toxicity than conventional anthracycline [135-137]. The PLD is a unique form of Doxo packed in a liposome coated with polyethylene glycol. This modification prevents plasma protein adsorption to the liposome surface and shows that PLDs can remain in the circulation much longer than non-PLD. Due to its increased permeability and retention effect, liposomes deliver drugs more specifically to cancer tissues, and limit the exposure of healthy cells to the drug thus reducing toxicity [136].

Experimental and clinical studies suggest that anthracycline/ Doxo-induced cardiotoxicity can also be prevented by administering
Coenzyme-Q10 (Co-Q10) before and during cancer chemotherapy, without interfering with the antineoplastic action of the drugs. CoQ10 is an essential component of the electron transport system and is probably the most important antioxidant in cardiac myocytes, where it has a protective effect against oxidative damage to mitochondrial proteins and mtDNA. Co-Q10 may prevent the anthracycline from being reduced to its semiquinone by the cytosolic NADH dehydrogenase activity. This is possibly due to competition for the enzyme active site. Co-Q10 administration seems to prevent damage to the cardiomyocytes mitochondria, thus, preventing the development of drug-induced cardiomyopathy [127].

Unfortunately, so far, the promising results obtained through antioxidants administration as protection against Doxo-induced cardiotoxicity were obtained in animal models and rarely translated into a similar protection in humans. The fact that Doxo cardiotoxicity may remain silent for decades has not motivated the physicians into prescribing drugs to counteract the possible Doxo injuries if these are not evident.

\subsection{Physical Activity as a Possible Alternative Strategy for Prevention of Anthracycline/Doxo-induced Toxicity}

Indeed, a non-pharmacological approach to prevent cardiac and muscle damage induced by Doxo is based on physical exercise and calorie restriction. Regular exercise improves metabolism and especially mitochondrial capacity in the hearts of former Doxo patients. A study showed that low-intensity aerobic exercise, concomitant with low-dose Doxo administration (cumulative dose of $4 \mathrm{mg} / \mathrm{kg}$ ) would mitigate the Doxo-induced cardiotoxicity while also improving the therapeutic efficacy of Doxo in a murine model of melanoma [138]. Exercise training protects against Doxoinduced myopathy in both heart and skeletal muscles, by reducing FoxO1 and FoxO3 expression, and the transcription of their target genes [i.e., atrogin-1/muscle atrophy F-box (MaFbx), muscle ring finger-1 (MuRF-1), and BCL2/adenovirus E1B $19 \mathrm{kDa}$ proteininteracting protein 3 (BNIP3)]. Furthermore, exercise increases PGC-1 $\alpha$ in both heart and skeletal muscles and the increased PGC-1 $\alpha$ expression is known to suppress FoxO activity [139] and to regulate mitochondrial biogenesis [140].

\subsection{Calorie Restriction may Resemble the Positive effects of Exercise in Anthracycline/Doxo-induced Toxicity}

A combined approach of low-dose caloric restriction (20\%) and resveratrol was used therapeutically to induce autophagy and to provide protection against Doxo-mediated toxicity in the hearts of 26-months-old rats [141]. The protective role of calorie restriction may be due, at least in part, to increased autophagic fluxes in cardiac tissue, suggesting the protective role of cardiac autophagy in removing damaged cell structures after Doxo treatment [142].

Other published data suggest that, in skeletal muscle, ghrelin, a potential cancer cachexia fighting agent, suppresses the Doxoinduced activation of apoptosis and enhances the cellular signaling of autophagy. This then exerts protective effects against Doxoinduced muscle toxicity [143]. Furthermore, ghrelin effectively improves cardiomyocyte survival and size maintenance by suppressing excessive autophagy through both ROS inhibition and mTOR induction by suppressing AMPK activity and by stimulating p38-MAPK activity [144].

\subsection{Oral Supplementation of Special Mixture of Aminoacids Maintains the Integrity and Function of the Muscle}

Recent data show that oral supplementation of special mixture of aminoacids maintains the integrity and function of the muscle, induces mitochondriogenesis, contains ROS production and inhibits apoptosis [145]. Furthermore, chronic oral essential amino acids (EAA) administered in aged rats significantly increased the 
expression and activation of mTOR and, possibly, mTOR activated metabolic pathways, which may lead to increased protein synthesis [145]. Further recent evidences revealed the important antiaging role of chronic EAA supplementation in mammals. It increased the average life span of mice, by increasing mitochondrial biogenesis and sirtuin 1 expression in primary cardiac and skeletal myocytes and in cardiac and skeletal muscle, via eNOS- and mTOR-mediated mechanisms. This was accompanied by enhanced physical endurance. Moreover, the ROS defense genes were upregulated, and ROS production was reduced [99]. EAA supplementation was also effective in reducing damage caused by alcohol in the liver and by rosuvastatin in the kidney [146, 147]. Together, these studies offer a rationale for exploring the role of EAA in preventing and controlling chemotherapy-induced toxicity.

To test this intriguing hypothesis we performed a pilot study using an experimental model in which acute cardiomyopathy was induced in male mice by a single i.p. injection of Doxo $(15 \mathrm{mg} / \mathrm{kg})$ [148]. A group of Doxo-treated mice was daily supplemented with an EAA mixture $(1.5 \mathrm{~g} / \mathrm{kg})$ for 14 days. The results (unpublished results) confirmed that Doxo has significant negative effects on the heart and body-mass of mice, inducing cardiomyocyte alteration and greatly impairing the distribution and morphology of mitochondria. Conversely, the EAA supplementation preserved whole body mass, cardiomyocyte architecture and mitochondrial integrity, thus counteracting the Doxo effects on autophagic paths (Corsetti's personal communication).

In addition we also studied the possible interference of EAA on Doxo toxicity in colon (HCT116), mammary gland (MCF7) and melanoma (M14) cancer cell lines in vitro. We observed that Doxo promotes cell apoptosis and EAA increase and does not counteract Doxo therapeutic efficacy on cancer cells. Unexpectedly, EAA, even in absence of Doxo, have a powerful apoptotic effect on cancer cells (unpublished results, Flati's personal communication).

These preliminary data, although obtained from experimental models of acute intoxication, may open a new non-pharmacological path to prevent/contain the onset of anthracycline-induced cardiotoxicity.

Double blind controlled studies in cancer bearing patients undergoing chemotherapy are in progress in different clinical research centers.

\section{CONCLUDING REMARKS}

Many studies have indicated that the regulation of cell homeostasis is very complex and involves many contemporarily positive and negative controlling messages, often with highly contrasting effects. Drugs may act on one or more cell growth rate controlling steps, but in a clinical setting they have often failed to fully reach their expectations. In our laboratory, we are exploring whether amino acids, (the active metabolites involved in both cell energy production and syntheses) may be used to modify, the expression and direction of metabolic fluxes and, possibly, drug responses.

Modulating mTOR, and its active complexes mTORC1 and 2 intertwined regulation, in different physiological environments and thus managing to modulate the prevalence of one or another mTOR complex activity, could be an important step towards achieving better cancer therapies. This strategy is thought to protect healthy cells from toxicity - as preliminary data have shown in mouse muscles and hearts - while amplifying therapeutic response in diseased animals.

Most probably, altering the essential to non-essential amino acid ratios is a means 1) to achieve physiologically protective goals and also 2) to unveil the pathways that underline the cancer cells peculiar efficiency in surviving to chemotherapy, 3) in ruling substrates availability and 4) controlling mTOR functional messages (survival or death).

\section{CONFLICT OF INTEREST}

The authors declare no conflict of interest except Francesco $\mathrm{S}$ Dioguardi who is inventor and owner of US patents $n^{\circ}$ :

-US6218420 B1. Compositions based on amino-acids, for preventing and treating alimentary overloads in conditions of elevate body nitrogen requirements, without causing calcium losses.

-US7973077 B2: Amino acid based compositions for the treatment of pathological conditions distinguished by insufficient mitochondrial function. V.F.

This work was in part supported by Fondo di Ateneo ex $60 \%$ to

\section{ACKNOWLEDGEMENTS}

We would like to thank Prof. Robert Coates (Language Centre, Bocconi University, Milan, Italy), medical writer, for his linguistic revision.

\section{REFERENCES}

[1] Salomão, E.M.; Toneto, A.T.; Silva, G.O.; Gomes-Marcondes, M.C.C. Physical exercise and a leucine-rich diet modulate the muscle protein metabolism in walker tumor-bearing rats. Nutr. Cancer, 2010, 62(8), 1095-1104.

[2] Argilés, J.M. Nutritional status at diagnosis is related to clinical outcomes in children and adolescents with cancer: A perspective from Central America. Cancer-associated malnutrition. Eur. J. Oncol. Nurs., 2005, 9, S39-S50.

[3] De Lorenzo, M.S.; Bajinnyam, E.; Vatner, D.E.; Abarzùa, P.; Vatner, S.F.; Rabson, A.B. Caloric restriction reduces growth of mammary tumors and metastases. Carcinogenesis, 2011, 32(9), 1381-1387.

[4] Luo, L.; Lu, A.M.; Wang, Y.; Hong, A.; Chen, Y.; Hu, J.; Li, X.; Qin, Z.H. Chronic resistance training activates autophagy and reduces apoptosis of muscle cells by modulating IGF-1 and its receptors, $\mathrm{Akt} / \mathrm{mTOR}$ and $\mathrm{Akt} / \mathrm{FOXO} 3 \mathrm{a}$ signaling in aged rats. Exp. Gerontol., 2013, 48(4), 427-436.

[5] Sherman, C.D.; Morton, J.J.; Mider, G.B. Potential sources of tumor nitrogen. Cancer Res., 1950, 10(6), 374-378.

[6] Davis, H.A.; Mider, G.B. The effect of ischemia on the free aminoacid content of tissues. Br. J. Cancer, 1951, 5(1), 148-151.

[7] Allison, J.B.; Wannemacher, R.W.; Hilf, R.; Hetzel, C.A. The effect of methionine supplementation upon the tumor-host relationship in the rat. J. Nutr., 1956, 59(1), 27-38.

[8] Greenstein, J.P. Some biochemical characteristic of morphologically separable cancers. Cancer Res., 1956, 16, 641-653.

[9] Albuquerque, R.C.R.; Baltar, V.T.; Marchioni, D.M.L. Breast cancer and dietary patterns: A systematic review. Nutr. Rev., 2014, 72(1), 1-17.

[10] Gonzalez, C.A. Nutrition and cancer: The current epidemiological evidence. Br. J. Nutr., 2006, 96(S1), S42-S45.

[11] Shaw, J.H.; Humberstone, D.A.; Douglas, R.G.; Koea, J. Leucine kinetics in patients with benign disease, non-weight-losing cancer, and cancer cachexia: Studies at the whole-body and tissue level and the response to nutritional support. Surgery, 1991, 109(1), 37-50.

[12] Scarabelli, T.M.; Pasini, E.; Stephanou, A.; Chen-Scarabelli, C.; Saravolatz, L.; Knight, R.A.; Latchman D.S.; Gardin, J.M. Nutritional supplementation with mixed essential aminoacids enhance myocyte survival, preserving mitochondrial functional capacity during ischemia-reperfusion injury. Am. J. Cardiol., 2004 93(8A), 35A-40A.

[13] Ignarro, L.J. A novel signal transduction mechanism for transcellular communication. Nitric Oxide, 2001, 16, 477-483.

[14] Anker, S.D.; Chaua, T.P.; Ponikowski, P.; Harrington, D.; Swan, J.W.; Kox, W.J.; Poole-Wilson, P.A.; Coats, A.J. Hormonal changes and catabolic/anabolic imbalance in chronic heart failure and their importance for cardiac cachexia. Circulation, 1997, 96, 526-534. 
[15] Pasini, E.; Aquilani, R.; Dioguardi, F.S.; D'Antona, G.; Gheorghiade, M.; Taegtmeyer, H. Hypercatabolic syndrome: Molecular basis and effects of nutritional supplementation with amino acids. Am. J. Cardiol., 2008, 101(11A), 11E-15E.

[16] Wolfe, R. The underappreciated role of muscle in health and disease. Am. J. Clin. Nutr., 2006, 84, 475-482.

[17] Babson, A.L.; Winnick, T. Protein transfer in tumor-bearing rats. Cancer Res., 1954, 14, 606-611.

[18] Besterman, J.M.; Airhart, J.A.; Low, R.B.; Rannels, D.E. Pinocytosis and intracellular degradation of exogenous protein: Modulation by aminoacids. J. Cell. Biol., 1983, 96, 1586-1591.

[19] Stehle, G.; Sinn, H.; Wunder, A.; Schrenk, H.H.; Stewart, J.C.; Hartung, G.; Maier-Borst, W.; Heene, D.L. Plasma protein (albumin) catabolism by the tumor itself-implications for tumor metabolism and the genesis of cachexia. Crit. Rev. Oncol. Hematol., 1997, 26, 77-100.

[20] Le Bricon, T.; Cynober, L.; Field, C.J.; Baracos, V.E. Supplemental nutrition with ornithine a-ketoglutarate in rats with cancer-associated cachexia: Surgical treatment of tumor improves efficacy of nutritional support. J. Nutr., 1995, 125, 2999-3010.

[21] Kraemer, J.W.T.; Ratamess, N.A.; Volek, J.S.; Häkkinen, K.; Rubin, M.R.; French, D.N.; Gómez, A.L.; McGuigan, M.R.; Scheett, T.P.; Newton, R.U.; Spiering, B.A.; Izquierdo, M.; Dioguardi, F.S. The effects of amino acid supplementation on hormonal responses to resistance training overreaching. Metabolism, 2006, 55, 282-291.

[22] Grolschl, M.; Knerr, I.; Topf, H.G.; Schmid, P.; Rascher W.; Rauh, M. Endocrine responses to the oral ingestion of a physiological dose of essential aminoacids in humans. J. Endocrinol., 2003, 179, 273-244.

[23] Dioguardi, F.S. Wasting and the substrate to energy controlled pathway: A role for insulin resistance and aminoacids. Am. J. Cardiol., 2004, 93(S), 6A-12A.

[24] Volpi, E.; Kobayashi, H.; Sheffield-Moore, M.; Mittendorfer, B.; Wolfe, R.R. Essential amino acids are primarily responsible for the amino acid stimulation of muscle protein anabolism in healthy elderly adults. Am. J. Clin. Nutr., 2003, 78, 250-258.

[25] Nisoli, E.; Cozzi, V.; Carruba. M. Amino Acids and mitochondrial biogenesis. Am. J. Cardiol., 2008, 101, 22E-25E.

[26] Fujita, S.; Dreyer, H.C.; Drummond, M.J.; Glynn, E.L.; Cadenas, J.G.; Yoshizawa, F.; Volpi, E.; Rasmussen, B.B. Nutrient signaling in the regulation of human muscle protein synthesis. J. Physiol., 2007, 582(2), 813-823.

[27] Noguchi, Y.; Young, J.D.; Aleman, J.O.; Hansen, M.E.; Kelleher, J.K.; Stephanopoulos, G. Effect of anaplerotic fluxes and amino acid availability on hepatic lipoapoptosis. J. Biol. Chem., 2009, 284(48), 33425-33436.

[28] Muto, Y.; Sato, S.; Watanabe, A.; Moriwaki, H.; Suzuki, K.; Kato, A.; Kato, M.; Nakamura, T.; Higuchi, K.; Nishiguchi, S.; Kumada, H.; Ohashi ,Y. Long-Term survival study (LOTUS) group. Overweight and obesity increase the risk for liver cancer in patients with liver cirrhosis and long-term oral supplementation with branched-chain amino acid granules inhibits liver carcinogenesis in heavier patients with liver cirrhosis. Hepatol. Res., 2006, 35, 204214.

[29] Layman, D.K. Dietary Guidelines should reflect new understandings about adult protein needs. Nutr. Metab., 2009, 6, 1218.

[30] Deldicque, L.; Theisen, D.; Francaux, M. Regulation of mTOR by amino acids and resistance exercise in skeletal muscle. Eur. $J$. Appl. Physiol., 2005, 94, 1-10.

[31] Guertin, D.A.; Sabatini, D.M. Defining the role of mTOR in cancer. Cancer Cell, 2007, 12, 9-22.

[32] Nijhout, H.F.; Callier, V. A new mathematical approach for qualitative modeling of the insulin-TOR-MAPK network. Front. Physiol., 2013, 4(245), 1-10.

[33] Evans, D.S.; Kapahi, P.; Hsueh, W.C.; Kokel, L. TOR signaling never gets old: Aging, longevity and TORC1 activity. Ageing Res. Rev., 2001, 10, 225-237.

[34] Cuzick, J.; Thorat, M.A.; Andriole, G.; Brawley, O.W.; Brown, P.H.; Culig, Z.; Eeles, R.A.; Ford, L.G.; Hamdy, F.C.; Holmberg, L.; Ilic, D.; Key, T.J.; La Vecchia, C.; Lilja, H.; Marberger, M.; Meyskens, F.L.; Minasian, L.M.; Parker, C.; Parnes, H.L.; Perner, S.; Rittenhouse, H.; Schalken, J.; Schmid, H.P.; Schmitz-Dräger, B.J.; Schröder, F.H.; Stenzl, A.; Tombal, B.; Wilt, T.J.; Wolk, A.
Prevention and early detection of prostate cancer. Lancet Oncol., 2014, 15(11), e484-492.

[35] Kollarova, H.; Azeem, K.; Tomaskova, H.; Horakova, D.; Prochazka, V.; Martinek, A.; Shonova, O.; Sevcikova, J.; Sevcikova, V.; Janout, V. Is physical activity a protective factor against pancreatic cancer? Bratisl. Lek. Listy., 2014, 115(8), 474478.

[36] Howell, A.; Anderson, A.S.; Clarke, R.B.; Duffy, S.W.; Evans, D.G.; Garcia-Closas, M.; Gescher, A.J.; Key, T.J.; Saxton, J.M.; Harvie, M.N. Risk determination and prevention of breast cancer. Breast Cancer Res., 2014, 16(5), 446.

[37] Courneya, K.S.; McKenzie, D.C.; Mackey, J.R.; Gelmon, K.; Friedenreich, C.M.; Yasui, Y.; Reid, R.D.; Vallerand, J.R.; Adams, S.C.; Proulx, C.; Dolan, L.B.; Wooding, E.; Segal, R.J. Subgroup effects in a randomised trial of different types and doses of exercise during breast cancer chemotherapy. Br. J. Cancer, 2014, 111(9), $1718-1725$

[38] Courneya, K.S.; Segal, R.J.; McKenzie, D.C.; Dong, H.; Gelmon, K.; Friedenreich, C.M.; Yasui, Y.; Reid, R.D.; Crawford, J.J.; Mackey, J.R. Effects of exercise during adjuvant chemotherapy on breast cancer outcomes. Med. Sci. Sport. Exerc., 2014, 46(9), 17441751

[39] Smuder, A.J.; Kavazis, A.N.; Min, K.; Powers, S.K. Exercise protects against doxorubicin-induced markers of autophagy signaling in skeletal muscle. J. Appl. Physiol., 2011, 111, 11901198

[40] Prado, C.M.; Baracos, V.E.; McCargar, L.J.; Reiman, T Mourtzakis, M.; Tonkin, K.; Mackey, J.R.; Koski, S.; Pituskin, E.; Sawyer, M.B. Sarcopenia as a determinant of chemotherapy toxicity and time to tumor progression in metastatic breast cancer patients receiving capecitabine treatment. Clin. Cancer Res., 2009, 15,2920 .

[41] Arends, J.; Bodoky, G.; Bozzetti, F.; Fearon, K.; Muscaritoli, M.; Selga, G.; Van Bokhorst-de van der Schueren, M.A.; von Meyenfeldt, M.; DGEM (German Society for Nutritional Medicine); Zürcher, G.; Fietkau, R.; Aulbert, E.; Frick, B.; Holm, M.; Kneba, M.; Mestrom, H.J.; Zander, A.; ESPEN (European Society for Parenteral and Enteral Nutrition). ESPEN guidelines on enteral nutrition: Non-surgical oncology. Clin. Nutr., 2006, 25, 245-259.

[42] Cousin, S.; Hollebecque, A.; Koscielny, S.; Mir, O.; Varga, A.; Baracos, V.E.; Soria, J.C.; Antoun, S. Low skeletal muscle is associated with toxicity in patients included in phase I trials. Invest. New Drugs, 2014, 32, 382-387.

[43] Awad, S.; Tan, B.H.; Cui, H.; Bhalla, A.; Fearon, K.C.; Parsons, S.L.; Catton, J.A.; Lobo, D.N. Marked changes in body composition following neoadjuvant chemotherapy for oesophagogastric cancer. Clin. Nutr., 2012, 31(1), 74-77.

[44] Taffel, M. Experiences in the treatment of neoplastic disease with nitrogen mustard. Yale J. Biol. Med., 1947, 19(6), 971-977.

[45] Garber, K. Targeting mTOR: Something old, something new. $J$. Natl. Cancer Inst., 2009, 101(5), 288-290.

[46] Carracedo, A.; Ma, L.; Teruya-Feldstein, J.; Rojo, F.; Salmena, L.; Alimonti, A.; Egia, A.; Sasaki, A.T.; Thomas, G.; Kozma, S.C.; Papa, A.; Nardella, C.; Cantley, L.C.; Baselga, J.; Pandolfi, P.P. Inhibition of mTORC1 leads to MAPK pathway activation through a PI3K-dependent feedback loop in human cancer. J. Clin. Invest., 2008, 118(9), 3065-3074.

[47] Morita, M.; Gravel, S.P.; Hulea, L.; Larsson, O.; Pollak, M.; StPierre, J.; Topisirovic, I. mTOR coordinates protein synthesis, mitochondrial activity and proliferation. Cell Cycle, 2015, 14(4), 473-480.

[48] Albert, V.; Hall, M.N. mTOR signaling in cellular and organismal energetics. Curr. Opin. Cell. Biol., 2014, 33(C), 55-66.

[49] Howell, J.J.; Manning, B.D. mTOR couples cellular nutrient sensing to organismal metabolic homeostasis. Trend. Endocrinol. Metab., 2011, 22(3), 94-102.

[50] Hara, K.; Maruki, Y.; Long, X.; Yoshino, K.; Oshiro, N.; Hidayat, S.; Tokunaga, C.; Avruch, J.; Yonezawa. K. Raptor, a binding partner of target of rapamycin (TOR), mediates TOR action. Cell, 2002, 110, 177-189.

[51] Sancak, Y.; Thoreen, C.C.; Peterson, T.R.; Lindquist, R.A.; Kang, S.A.; Spooner, E.; Carr, S.A.; Sabatini, D.M. PRAS40 is an insulinregulated inhibitor of the mTORC1 protein kinase. Mol. Cell, 2007, 25(6), 903-915. 
[52] Wiza, C.; Nascimento, E.B.; Ouwens, D.M. Role of PRAS40 in Akt and mTOR signaling in health and disease. Am. J. Physiol. Endocrinol. Metab., 2012, 302(12), E1453-1460.

[53] Thedieck, K.; Polak, P.; Kim, M.L.; Molle, K.D.; Cohen, A.; Jenö, P.; Arrieumerlou, C.; Hall, M.N. PRAS40 and PRR5-like protein are new mTOR interactors that regulate apoptosis. PLoSOne, 2007, 2(11), e1217.

[54] Pearce, L.R.; Huang, X.; Boudeau, J.; Pawłowski, R.; Wullschleger, S.; Deak, M.; Ibrahim, A.F.; Gourlay, R.; Magnuson, M.A.; Alessi, D.R. Identification of Protor as a novel Rictorbinding component of mTOR complex-2. Biochem J., 2007, 405, 513-522.

[55] Sarbassov, D.D.; Ali, S.M.; Kim, D.H.; Guertin, D.A.; Latek, R.R.; Erdjument-Bromage, H.; Tempst, P.; Sabatini, D.M. Rictor, a novel binding partner of mTOR, defines a rapamycin-insensitive and raptor-independent pathway that regulates the cytoskeleton. Curr. Biol., 2004, 14, 1296-1302.

[56] Jacinto, E.; Facchinetti, V.; Liu, D.; Soto, N.; Wei, S.; Jung, S.Y.; Huang, Q.; Qin, J.; Su, B. SIN1/MIP1 maintains rictor-mTOR complex integrity and regulates Akt phosphorylation and substrate specificity. Cell, 2006, 127, 125-137.

[57] Yang, Q.; Inoki, K.; Ikenoue, T.; Guan, K.L. Identification of Sin1 as an essential TORC2 component required for complex formation and kinase activity. Gen. Dev., 2006, 20, 2820-2832.

[58] Peterson, T.R.; Laplante, M.; Thoreen, C.C.; Sancak, Y.; Kang, S.A.; Kuehl, W.M.; Gray, N.S.; Sabatini, D.M. Deptor is an mTOR inhibitor frequently overexpressed in multiple myeloma cells and required for their survival. Cell, 2009, 137(5), 873-86.

[59] Proud, C.G. Dynamic balancing: Deptor tips the scales. J. Mol. Cell. Biol., 2009, 1(2), 61-63.

[60] Navé, B.T.; Ouwens, M.; Withers, D.J.; Alessi, D.R.; Shepherd, P.R. Mammalian target of rapamycin is a direct target for protein kinase B: Identification of a convergence point for opposing effects of insulin and amino-acid deficiency on protein translation. Biochem J., 1999, 344(Pt 2), 427-431.

[61] Mihaylova, M.M.; Shaw, R.J. The AMPK signalling pathway coordinates cell growth, autophagy and metabolism. Nat. Cell. Biol., 2011, 13, 1016-1023.

[62] Hara, K.; Yonezawa, K.; Weng, Q.P.; Kozlowski, M.T.; Belham, C.; Avruch, J. Amino acid sufficiency and mTOR regulate p70 S6 kinase and eIF-4E BP1 through a common effector mechanism. $J$. Biol. Chem., 1998, 273, 14484-14494.

[63] Wang, X.; Campbell, L.E.; Miller, C.M.; Proud, C.G. Amino acid availability regulates p70 S6 kinase and multiple translation factors. Biochem. J., 1998, 334(Pt 1), 261-267.

[64] Avruch, J.; Long, X.; Ortiz-Vega, S.; Rapley, J.; Papageorgiou, A.; Dai, N. Amino acid regulation of TOR complex 1. Am. J. Physiol. Endocrinol. Metab., 2009, 296, E592-602.

[65] Nicklin, P.; Bergman, P.; Zhang, B.; Triantafellow, E.; Wang, H.; Nyfeler, B.; Yang, H.; Hild, M.; Kung, C.; Wilson, C.; Myer, V.E.; MacKeigan, J.P.; Porter, J.A.; Wang, Y.K.; Cantley, L.C.; Finan, P.M.; Murphy, L.O. Bidirectional transport of amino acids regulates mTOR and autophagy. Cell, 2009, 136, 521-534.

[66] Zoncu, R.; Bar-Peled, L.; Efeyan, A.; Wang, S.; Sancak, Y.; Sabatini, D.M. mTORC1 senses lysosomal amino acids through an inside-out mechanism that requires the vacuolar $\mathrm{H}(+)$-ATPase. Science, 2011, 334, 678-683.

[67] Sancak, Y.; Peterson, T.R.; Shaul, Y.D.; Lindquist, R.A.; Thoreen, C.C.; Bar-Peled, L.; Sabatini, D.M. The Rag GTPases bind raptor and mediate amino acid signaling to mTORC1. Science, 2008, 320, 1496-1501.

[68] Sancak, Y.; Bar-Peled, L.; Zoncu, R.; Markhard, A.L.; Nada, S.; Sabatini, D.M. Ragulator-Rag complex targets mTORC1 to the lysosomal surface and is necessary for its activation by aminoacids. Cell, 2010, 141, 290-303.

[69] Bar-Peled, L.; Schweitzer, L.D.; Zoncu, R.; Sabatini, D.M. Ragulator Is a GEF for the Rag GTPases that Signal Amino Acid Levels to mTORC1. Cell, 2012, 150, 1196-1208.

[70] Garami, A.; Zwartkruis, F.J.; Nobukuni, T.; Joaquin, M.; Roccio, M.; Stocker, H.; Kozma, S.C.; Hafen, E.; Bos, J.L.; Thomas, G. Insulin activation of Rheb, a mediator of mTOR/S6K/4E-BP signaling, is inhibited by TSC1 and 2. Mol. Cell, 2003, 11, 14571466.

[71] Inoki, K.; Li, Y.; Xu, T.; Guan, K.L. Rheb GTPase is a direct target of TSC2 GAP activity and regulates mTOR signaling. Gen. Dev., 2003, 17, 1829-1834.
[72] Gao, X.; Zhang, Y.; Arrazola, P.; Hino, O.; Kobayashi, T.; Yeung, R.S.; Ru, B.; Pan, D. Tsc tumour suppressor proteins antagonize amino-acid-TOR signalling. Nat. Cell. Biol., 2002, 4, 699-704.

[73] Inoki, K.; Li, Y.; Zhu, T.; Wu, J.; Guan, K.L. TSC2 is phosphorylated and inhibited by Akt and suppresses mTOR signalling. Nat. Cell. Biol., 2002, 4, 648-657.

[74] Jewell, J.L.; Guan, K.L. Nutrient signaling to mTOR and cell growth. Trend. Biochem. Sci., 2013, 38(5), 233-242.

[75] Laplante, M.; Sabatini, D.M. mTOR signaling in growth control and disease. Cell, 2012, 49(2), 274-293.

[76] Averous, J.; Lambert-Langlais, S.; Carraro, V.; Gourbeyre, O.; Parry, L.; B'Chir, W.; Muranishi, Y.; Jousse, C.; Bruhat, A.; Maurin, A.C.; Proud, C.G.; Fafournoux, P. Requirement for lysosomal localization of mTOR for its activation differs between leucine and other amino acids. Cell Signal., 2014, 26(9), 19181927.

[77] Sabatini, D.M. mTOR and cancer: Insights into a complex relationship. Nat. Rev. Cancer, 2006, 6, 729-734.

[78] Guertin, D.A.; Sabatini, D.M. Defining the role of mTOR in cancer. Cancer Cell, 2007, 12, 9-22.

[79] Muto, Y.; Sato, S.; Watanabe, A.; Moriwaki, H.; Suzuki, K.; Kato, A.; Kato, M.; Nakamura, T.; Higuchi, K.; Nishiguchi, S.; Kumada, H.; Ohashi, Y.; Long-Term survival study (LOTUS) group. Overweight and obesity increase the risk for liver cancer in patients with liver cirrhosis and long-term oral supplementation with branched-chain amino acid granules inhibits liver carcinogenesis in heavier patients with liver cirrhosis. Hepatol. Res., 2006, 35, 204214.

[80] Nakano, M.; Nakashima, A.; Nagano, T.; Ishikawa, S.; Kikkawa, U.; Kamada, S. Branched-chain amino acids enhance premature senescence through mammalian target of rapamycin complex imediated upregulation of $\mathrm{p} 21$ protein. PLoS One, 2013, 8(11), e80411.

[81] Hagiwara, A.; Nishiyama, M.; Ishizaki, S. Branched-chain amino acids prevent insulin-induced hepatic tumor cell proliferation by inducing apoptosis through mTORC1 and mTORC2-dependent mechanisms. J. Cell. Physiol., 2012, 227(5), 2097-105.

[82] Nishitani, S.; Horie, M.; Ishizaki, S.; Yano, H. Branched chain amino acid suppresses hepatocellular cancer stem cells through the activation of mammalian target of rapamycin. PLoS One, 2013, 8(11), e82346.

[83] Julien, L.A.; Carriere, A.; Moreau, J.; Roux, PP. mTORC1activated S6K1 phosphorylates Rictor on threonine 1135 and regulates mTORC2 signaling. Mol. Cell. Biol., 2010, 30, 908-1021.

[84] Mimeault, M.; Johansson, S.L.; Batra, K.S. Pathobiolgical implications of the expression of EGFR, pAKT, NF-kappaB and MIC-1 in prostate cancer stem cells and their progenies. PLoS One, 2012, 7(2), e31919.

[85] Han, M.; Liu, M.; Wang, Y.; Chen, X.; Xu, J.; Sun, Y.; Zhao, L.; Qu, H.; Fan, Y.; Wu, C. Antagonism of mir-21 reverses eptherial mesenchymal trasition and cancer stem cell phenotype through Akt/ERK1/2 inactivation by targeting PTEN. PLoS One, 2012, 7(6), e39520.

[86] Guertin, D.A.; Stevens, D.M.; Saitoh, M.; Kinkel, S.; Crosby, K.; Sheen, J.H.; Mullholland, D.J.; Magnuson, M.A.; Wu, H.; Sabatini, D.M. mTOR complex 2 is required for the development of prostate cancer induced by Pten loss in mice. Cancer Cell, 2009, 15, 148159.

[87] Pearce, L.R.; Komander, D.; Alessi, D.R. The nuts and bolts of AGC protein kinases. Nat. Rev. Mol. Cell. Biol. 2010, 11(1), 9-22.

[88] Zoncu, R.; Efeyan, A.; Sabatini, D.M. mTOR: From growth signal integration to cancer, diabetes and ageing. Nat. Rev. Mol. Cell. Biol., 2011, 12, 2-35.

[89] Pópulo, H.; Lopes, J.M.; Soares, P. The mTOR signalling pathway in human cancer. Int. J. Mol. Sci., 2012, 13, 1886-1918.

[90] Tato, I.; Bartrons, R.; Ventura, F.; Rosa, J.L. Amino acids activate mammalian target of rapamycin complex 2 (mTORC2) via PI3K/Akt signaling. J. Biol. Chem., 2011, 286(8), 6128-6142.

[91] Vlahakis, A.; Powers, T. A role for TOR complex 2 signaling in promoting autophagy. Autophagy, 2014, 10(11), 2085-2086.

[92] Yu, L.; McPhee, C.K.; Zheng, L.; Mardones, G.A.; Rong, Y.; Peng, J.; Mi, N.; Zhao, Y.; Liu, Z.; Wan, F.; Hailey, D.W.; Oorschot, V.; Klumperman, J.; Baehrecke, E.H.; Lenardo, M.J. Termination of autophagy and reformation of lysosomes regulated by mTOR. Nature, 2010, 465(7300), 942-946. 
[93] Vendelbo, M.H.; Moeller, A.B.; Christensen, B.; Nellemann, B.; Clasen, B.F.; Nair, K.S.; Jørgensen, J.O.; Jessen, N.; Møller, N. Fasting increases human skeletal muscle net phenylalanine release and this is associated with decreased mTOR signaling. PloS One, 2014, 9(7), e102031.

[94] Hresko, R.C.; Mueckler, M. mTOR rictor is the Ser473 kinase for Akt/protein kinase B in 3T3-L1 adipocytes. J. Biol. Chem., 2005, 280(49), 40406-40416.

[95] Gual, P.; Le Marchand-Brustel, Y.; Tanti, J.F. Positive and negative regulation of insulin signaling through IRS-1 phosphorylation. Biochimie, 2005, 87(1), 99-109.

[96] Hsu, P.P.; Kang, S.A.; Rameseder, J.; Zhang, Y.; Ottina, K.A.; Lim, D.; Peterson, T.R.; Choi, Y.; Gray, N.S.; Yaffe, M.B.; Marto, J.A.; Sabatini, D.M. The mTOR-regulated phosphoproteome reveals a mechanism of mTORC1-mediated inhibition of growth factor signaling. Science, 2011, 332(6035), 1317-1322.

[97] Yu, Y.; Yoon, S.O.; Poulogiannis, G.; Yang, Q.; Ma, X.M.; Villén, J.; Kubica, N.; Hoffman, G.R.; Cantley, L.C.; Gygi, S.P.; Blenis, J. Phosphoproteomic analysis identifies Grb10 as an mTORC1 substrate that negatively regulates insulin signaling. Science, 2011, 332(6035), 1322-1326.

[98] Liu, P.; Guo, J.; Gan, W.; Wei, W. Dual phosphorylation of Sin 1 at T86 and T398 negatively regulates mTORC2 complex integrity and activity. Protein Cell, 2014, 5(3), 171-177.

[99] D’Antona, G.; Ragni, M.; Cardile, A.; Tedesco, L.; Dossena, M.; Bruttini, F.; Caliaro, F.; Corsetti, G.; Bottinelli, R.; Carruba, M.O.; Valerio, A.; Nisoli, E. Branched-chain amino acid supplementation promotes survival and supports cardiac and skeletal muscle mitochondrial biogenesis in middle-aged mice. Cell Metab., 2010, $12,362-372$

[100] Flati, V.; Caliaro, F.; Speca, S.; Corsetti, G.; Cardile, A.; Nisoli, E.; Bottinelli, R.; D'Antona, G. Essential amino acids improve insulin activation of AKT/MTOR signaling in soleus muscle of aged rats. Int. J. Immunopathol. Pharmacol., 2010, 23(1), 81-89.

[101] Pansarasa, O.; Flati, V.; Corsetti, G.; Brocca, L.; Pasini, E.; D'Antona, G. Oral amino acid supplementation improves ageinduced sarcopenia in elderly rats. Am. J. Cardiol., 2008, 101(11A), 35E-41E.

[102] Efeyan, A.; Zoncu, R.; Sabatini, D.M. Amino acids and mTORC1: From lysosomes to disease. Trend. Mol. Med., 2012, 18, 524-533.

[103] Weiss, R.B. The anthracyclines: Will we ever find a better doxorubicin? Semin. Oncol., 1992, 19, 670-686.

[104] Hortobagyi, G.N. Anthracyclines in the treatment of cancer: An overview. Drugs, 1997, 54(4), 1-7.

[105] Maluf, F.C.; Spriggs, D. Anthracyclines in the treatment of gynecologic malignancies. Gynecol. Oncol., 2002, 85, 18-31.

[106] Kremer, L.; Van Dalen, E.; Offringa, M.; Ottenkamp, J.; Voûte, P. Anthracycline-induced clinical heart failure in a cohort of 607 children: Long-term follow-up study. J. Clin. Oncol., 2001, 19(1), 191-196.

[107] Swain, S.M.; Whaley, F.S.; Ewer, M.S. Congestive heart failure in patients treated with doxorubicin: A retrospective analysis of three trials. Cancer, 2003, 97(11), 2869-2879.

[108] Takemura, G.; Fujiwara, H. Doxorubicin-induced cardiomyopathy from the cardiotoxic mechanisms to management. Prog. Cardiovasc. Dis., 2007, 49(5), 330-352.

[109] Tewey, K.M.; Rowe, T.C.; Yang, L.; Halligan, B.D.; Liu, L.F. Adriamycin-induced DNA damage mediated by mammalian DNA topoisomerase II. Science, 1984, 226, 466-468.

[110] Zhang, S.; Liu, X.; Bawa-Khalfe, T.; Lu, L.S.; Lyu, Y.L.; Liu, L.F.; Yeh, E.T. Identification of the molecular basis of doxorubicininduced cardiotoxicity. Nat. Med., 2012, 18(11), 1639-1642.

[111] Vavrova, A.; Jansova, H.; Mackova, E.; Machacek, M.; Haskova, P.; Tichotova, L.; Sterba, M.; Simunek, T. Catalytic inhibitors of topoisomerase II differently modulate the toxicity of anthracyclines in cardiac and cancer cells. PLoS One, 2013, 8(10), e76676.

[112] Sarvazyan, N. Visualization of doxorubicin-induced oxidative stress in isolated cardiac myocytes. Am. J. Physiol. 1996, 271, H2079-H2085.

[113] Konorev, E.A.; Kennedy, M.C.; Kalyanaraman, B. Cell permeable superoxide dismutase and glutathione peroxidase mimetics afford superior protection against doxorubicin-induced cardiotoxicity: The role of reactive oxygen and nitrogen intermediates. Arch. Biochem. Biophys., 1999, 368, 421-428.

[114] Gewirtz, D.A. A critical evaluation of the mechanisms of action proposed for the antitumor effects of the anthracycline antibiotics adriamycin and daunorubicin. Biochem. Pharmacol., 1999, 57, 727-741.

[115] Minotti, G.; Menna, P.; Salvatorelli, E.; Cairo, G.; Gianni, L. Anthracyclines: Molecular advances and pharmacologic developments in antitumor activity and cardiotoxicity. Pharmacol. Rev., 2004, 56(2), 185-229.

[116] Myers, C.E.; McGuire, W.P.; Liss, R.H.; Ifrim, I.; Grotzinger, K.; Young; R.C. Adriamycin: The role of lipid peroxidation in cardiac toxicity and tumor response. Science, 1977, 197, 165-167.

[117] Adachi, K.; Fujiura, Y.; Mayumi, F.; Nozuhara, A.; Sugiu, Y.; Sakanashi, T.; Hidaka, T.; Toshima, H. A deletion of mitochondrial DNA in murine doxorubicin-induced cardiotoxicity. Biochem. Biophys. Res. Commun.,1993, 195, 945-951.

[118] Zhou, S.; Palmeira, C.M.; Wallace, K.B. Doxorubicin-induced persistent oxidative stress to cardiac myocytes. Toxicol. Lett., 2001, 121, 151-157.

[119] Faber, M.; Coudray, C.; Hida, H.; Mousseau, M.; Favier, A. Lipid peroxidation products, and vitamin and trace element status in patients with cancer before and after chemotherapy including Adriamycin: A preliminary study. Biol. Trace. Elem. Res., 1995, 47, 117-123.

[120] Erhola, M.; Kellokumpu-Lehtinen, P.; Metsa-Ketela, T.; Alanko, K.; Nieminen, M.M. Effects of anthracyclin-based chemotherapy on total plasma antioxidant capacity in small cell lung cancer patients. Free Radic. Biol. Med., 1996, 21, 383-390.

[121] Sangeetha, P.; Das, U.N.; Koratkar, R,; Suryaprabha, P. Increase in free radical generation and lipid peroxidation following chemotherapy in patients with cancer. Free Radic. Biol. Med., 1990, 8, 15-19.

[122] Faure, H.; Coudray, C.; Mousseau, M.; Ducros, V.; Douki, T.; Bianchini, F.; Cadet, J.; Favier, A. 5-Hydroxymethyluracil excretion, plasma TBARS and plasma antioxidant vitamins in Adriamycintreated patients. Free Radic. Biol. Med., 1996, 20(7), 979-983.

[123] Bachur, N.R.; Gee, M.V.; Friedman, R.D. Nuclear catalyzed antibiotic free radical formation. Cancer Res. 1982, 42, 1078-1081.

[124] Sinha, B.K.; Katki, A.G.; Batist, G.; Cowan, K.H.; Myers, C.E. Adriamycin-stimulated hydroxyl radical formation in human breast tumor cells. Biochem. Pharmacol., 1987, 36, 793-796.

[125] Kaiserova, H.; Simunek, T.; Sterba, M.; Den Hartog, G.J.; Schröterová, L.; Popelová, O.; Gersl, V.; Kvasnicková, E.; Bast, A New iron chelators in anthracycline-induced cardiotoxicity. Cardiovasc. Toxicol., 2007, 7(2), 145-150.

[126] Quiles, J.L.; Huertas, J.R.; Battino, M.; Mataix, J.; RamirezTortosa, M.C. Antioxidant nutrients and adriamycin toxicity. Toxicology, 2002, 180(1), 79-95.

[127] Conklin, K.A. Coenzyme Q10 for prevention of anthracyclineinduced cardiotoxicity. Integr. Cancer Ther., 2005, 4(2), 110-130.

[128] Hjalmarson, A.; Waagstein, F. The role of beta-blockers in the treatment of cardiomyopathy and ischaemic heart failure. Drugs, 1994, 47, 31-40.

[129] Shaddy, R.E.; Olsen, S.L.; Bristow, M.R.; Taylor, D.O.; Bullock, E.A.; Tani, L.Y.; Renlund, D.G. Efficacy and safety of metoprolol in the treatment of doxorubicin-induced cardiomyopathy in pediatric patients. Am. Heart. J., 1995, 129, 197-199.

[130] Luthy, A.; Furrer, M.; Waser, M.; Maggiorini, M.; Pluess, H.J.; Real, F.; Weiss, B.; Gallino, A.; Turina, M. Orthotopic heart transplantation: An efficient treatment in a young boy with doxorubicin-induced cardiomyopathy. J. Heart. Lung. Transplant., 1992, 11, 815-816.

[131] Arico, M.; Nespoli, L.; Pedroni, E.; Bonetti, F.; Vigano, M.; Burgio, G.R. Heart transplantation in a child with doxorubicininduced cardiomyopathy. N. Engl. J. Med., 1988, $319(20), 1353$.

[132] Thomas, X.; Le, Q.H.; Fiere, D. Anthracycline related toxicity requiring cardiac transplantation in long-term disease-free survivors with acute promyelocytic leukemia. Ann. Hematol., 2002, 81, 504-507.

[133] Singal, P.K.; Iliskovic, N. Doxorubicin-induced cardiomyopathy. N. Engl. J. Med., 1998, 339, 900-905.

[134] Indu, R.; Azhar, T.S.; Nair, A.; Nair, C.K. Amelioration of doxorubicin induced cardio-and hepato-toxicity by carotenoids. $J$. Cancer Res. Ther., 2014, $10(1), 62-67$.

[135] O'Shaughnessy, J. Liposomal anthracyclines for breast cancer: An overview. The Oncologist, 2003, 8 Suppl.2, 1-2.

[136] Green, A.E.; Rose, P.G. Pegylated liposomal doxorubicin in ovarian cancer. Int. J. Nanomedicine, 2006, 1, 229-239. 
[137] Lien, M.Y.; Liu, L.C; Wang, H.C.; Yeh, M.H.; Chen, C.J.; Yeh, S.P.; Bai, L.Y.; Liao, Y.M.; Lin, C.Y.; Hsieh, C.Y.; Lin, C.C.; Li, L.Y.; Lin, P.H.; Chiu, C.F. Safety and efficacy of pegylated liposomal doxorubicin-based adjuvant chemotherapy in patients with Stage I-III Triple-negative breast cancer. Anticancer Res., 2014, 34(12), 7319-7326.

[138] Sturgeon, K.; Schadler, K.; Muthukumaran, G.; Ding, D.; Bajulaiye, A.; Thomas, N.J.; Ferrari, V.; Ryeom, S.; Libonati, J.R. Concomitant low-dose doxorubicin treatment and exercise. Am. J. Physiol. Regul. Integr. Comp. Physiol., 2014, 307(6), R685-692.

[139] Kavazis, A.N.; Smuder, A.J.; Powers, S.K. Effects of short-term endurance exercise training on acute doxorubicin-induced FoxO transcription in cardiac and skeletal muscle. J. Appl. Physiol., 2014, 117(3), 223-230.

[140] Kelly, D.P.; Scarpulla, R.C. Transcriptional regulatory circuits controlling mitochondrial biogenesis and function. Gen. Dev., 2004, 15, 357-368.

[141] Dutta, D.; Xu, J.; Dirain, M.L.; Leeuwenburgh, C. Calorie restriction combined with resveratrol induces autophagy and protects 26-month-old rat hearts from doxorubicin-induced toxicity. Free Radic. Biol. Med., 2014, 74, 252-262.

[142] Carvalho, F.S.; Burgeiro, A.; Garcia, R.; Moreno, A.J.; Carvalho, R.A.; Oliveira, P.J. Doxorubicin-induced cardiotoxicity: From bioenergetic failure and cell death to cardiomyopathy. Med. Res. Rev., 2014, 34(1), 106-35.

[143] Yu, A.P.; Pei, X.M.; Sin, T.K.; Yip, S.P.; Yung, B.Y.; Chan, L.W.; Wong, C.S.; Siu, P.M. Acylated and unacylated ghrelin inhibit doxorubicin-induced apoptosis in skeletal muscle. Acta Physiol., 2014, 211(1), 201-213.

[144] Wang, X.; Wang, X.L.; Chen, H.L.; Wu, D.; Chen, J.X.; Wang, X.X.; Li, R.L.; He, J.H., Mo, L.; Cen, X.; Wei, Y.Q.; Jiang, W. Ghrelin inhibits doxorubicin cardiotoxicity by inhibiting excessive autophagy through AMPK and p38-MAPK. Biochem. Pharmacol., 2014, 88(3), 334-350.

[145] Corsetti, G.; Pasini, E.; D’Antona, G.; Nisoli, E.; Flati, V.; Assanelli, D.; Dioguardi, F.S.; Bianchi, R. Morphometric changes induced by amino acid supplementation in skeletal and cardiac muscles of old mice. Am. J. Cardiol., 2008, 101(11A), 26E-34E.

[146] Corsetti, G.; Stacchiotti, A.; Tedesco, L.; D'Antona, G.; Pasini, E.; Dioguardi, F.S.; Nisoli, E.; Rezzani, R. Essential amino acid supplementation decreases liver damage induced by chronic ethanol consumption in rats. Int J. Immunopathol. Pharmacol., 2011, 24(3), 611-619.

[147] Corsetti, G.; D’Antona, G.; Ruocco, C; Stacchiotti, A.; Romano, C.; Tedesco, L.; Dioguardi, F.S.; Rezzani, R.; Nisoli, E. Dietary supplementation with essential amino acids boots the beneficial effects of rosuvastatin on mouse kidney. Amino Acids, 2014, 46(9), 2189-2203.

[148] Suliman, H.B.; Carraway, M.S.; Ali, A.S.; Reynolds, C.M.; WeltyWolf, C.E.; Piantadosi, C.A. The $\mathrm{CO} / \mathrm{HO}$ system reverses inhibition of mitochondrial biogenesis and prevents murine doxorubicin cardiomyopathy. J. Clin. Invest., 2007, 117, 37303741 . 